\title{
Study of the Viability of the Departmental Health Insurance Unit in the Health District of Koungheul (Senegal)
}

\author{
Mamadou Makhtar M. Backe Leye ${ }^{1, ~ *, ~ O u m a r ~ B a s s o u m ~}{ }^{1}$, Ndeye Marème Sougou ${ }^{1}$, Marc $\operatorname{Raffinot}^{2}$, \\ Anta Tal Dia ${ }^{1}$ \\ ${ }^{1}$ Department of Preventive Medicine and Public Health, University Cheikh Anta Diop, Dakar, Senegal \\ ${ }^{2}$ Department of Organization Sciences, University Paris Dauphine, Paris, France
}

Email address:

mamadou.leye $a$ yahoo.fr (M. M. M. B. Leye), mamadou.leye $a$ ucad.edu.sn (M. M. M. Leye)

${ }^{*}$ Corresponding author

\section{To cite this article:}

Mamadou Makhtar M. Backé Leye, Oumar Bassoum, Ndeye Marème Sougou, Marc Raffinot, Anta Tal Dia. Study of the Viability of the Departmental Health Insurance Unit in the Health District of Koungheul (Senegal). Central African Journal of Public Health.

Vol. 5, No. 4, 2019, pp. 156-164. doi: 10.11648/j.cajph.20190504.14

Received: March 25, 2019; Accepted: June 17, 2019; Published: July 1, 2019

\begin{abstract}
The promotion of departmental units of health insurance (UDAM) is an essential path advocated by the State of Senegal to access to universal health coverage. The UDAM is a departmental mutual, professionalized with an expanded package of covered services and allowing early recourse of beneficiary patients to the public health structures of the district. After two years of implementation (2014-2015) from this initiative in a pilot phase, this work is to study the viability of UDAM Koungheul. A quantitative and qualitative evaluation study was conducted from July 20 to August 15, 2016. For the quantitative part, the study population of all records (logs and records) of members of UDAM Koungheul. A comprehensive recruitment files was conducted. An observation grid was crafted to collect data. As for the qualitative aspect, it was the UDAM officials, members, and non-members. Of individual interviews and focus group guides were used to collect the perceptions of these different targets on UDAM. Quantitative data were entered and analyzed using Excel 2007. Content analysis of about was conducted for qualitative data. Administratively, the UDAM had a good overall score of its operation tracking quality with $85 \%$ in 2014 and $100 \%$ in 2015 but gaps were noted in the use of some tools for managing and monitoring its operation. Functionally, the number of members and beneficiaries increased during 2015 with rates of monthly recoveries were around $100 \%$. The penetration rate increased from $2 \%$ to $8 \%$ from 2014 to 2015 . Technically, the beneficiaries of the least supported UDAM benefit costs covered compared to non-beneficiaries. Excluding this benefit to populations, UDAM was submitted the risks of abuse and adverse selection. Financially and economically, loss of membership fees failed to cover the cost of benefits with ratios of 52\% (2014) and 55\% (2015). The capital remained insufficient to cover its operating expenses and investment. Operating expense ratios for 2014 and 2015 were $85 \%$ and $176 \%$ respectively. The own financing rate increased from $62 \%$ to $35 \%$ in 2015 . Apart from administrative and operational viabilities, other sustainability dimensions: technical, financial and technical threatened once the partner withdraws. Thus, it is important that the additional funding is UDAM able to fill the financial gap with the withdrawal of a partner to face the charges and to strengthen its outreach activities in order to join the people and retain members.
\end{abstract}

Keywords: Risk Prevention, Health Insurance, Mutual, Viability

\section{Introduction}

In Senegal, the percentages of women and men with no medical coverage are $94 \%$ and $92 \%$ respectively [1]. In 2012, the issue of UHC for Senegalese families was reaffirmed as a strong commitment to achieving the Sustainable
Development Goals (SDGs). This priority resulted in the inclusion of UHC as one of the strategic axes of the National Health Development Program (PNDS) 2009-2018 and the National Strategy for Economic and Social Development (SNDES) 2013-2017 through its axis 2: “Accelerating access to basic social services, social protection and sustainable 
development" [2]. The new orientation of the Government of Senegal focuses on the informal and rural sector through community health mutuals as an essential strategic axis for achieving UHC. One of the objectives is "One local community, one mutual health insurance at least". It is in this dynamic that a departmental unit of health insurance (UDAM) has been set up since February 2014 at the level of the department of Koungheul. Underutilization of care services is noted in this department where the majority of the population is poor. As a result, this population cannot cope with direct payment, especially since the flat rates applied are considered high in relation to their daily income. In fact, in terms of the demand for care, regardless of free health initiatives (the sesame plan, free health care for children under 5 years and cesarean sections), the Koungheul populations continue to bear the costs of health care. The payment of a flat rate. To overcome these difficulties, a departmental mutual is set up under the Health Supply and Demand Support Program (PAODES) to promote people's buy-in. Membership in the departmental mutual will be a good alternative to the reduction of direct payment given the financial contributions supported by the PAODES, the UDAM and the State. Recourse to the health mutual scheme as a means of financing health is only of interest if its viability as an organization is guaranteed [3]. The department of Koungheul which is our frame of study, is located in the extreme East of the Kaffrine region $350 \mathrm{~km}$ from Dakar. The population of Koungheul represents $29 \%$ of the total population of the Kaffrine region. In 2014, it was estimated at 179,201 inhabitants with a density of 32 inhabitants per $\mathrm{km}^{2}$ and a rural population representing $80 \%$. On the economic front, the department is one of the poorest departments in Senegal with a poverty rate of $52 \%$ according to the poverty monitoring survey in Senegal [4]. The labor force works in an informal sector where incomes are generally low and precarious. Moreover, this part of the population does not benefit or does very little from social protection. The economy is essentially based on agriculture, livestock and informal trade. It is the main income generating activity in the department. It is an industry that employs more than $60 \%$ of the workforce. According to the National Agency of Statistics and Demography, in 2014 agricultural households represented $84.6 \%$ in the department [5]. In terms of health, the district has 01 type II health center with an operating theater, and 18 functional health posts. In terms of the demand for care, other than the free health initiatives (sesame plan, free care for children under 5 years and cesarean section), a UDAM was set up to facilitate access to care for populations within the district. Set up on May 3, 2014, Koungheul's UDAM won the bargaining challenge with the small health mutuals that ended up being absorbed by it in order to set up a departmental health mutual, professionalized, including an agreement with all Koungheul district health posts and health center with a wider package of services.

After two years of experience, it seems appropriate to evaluate the viability of the UDAM at the Koungheul department.

\section{Methodology}

This is a quantitative and qualitative evaluative study, which took place from July 20 to August 15, 2016.

\subsection{Quantitative Survey}

\subsubsection{Study Population}

The study population was constituted by all the files (registers and membership records, activity reports) of the UDAM of Koungheul.

Included were records (registers and membership records, activity reports) that belonged to the UDAM.

\subsubsection{Sampling}

Comprehensive recruitment of files meeting the inclusion criteria was completed.

\subsubsection{Collection Tools and Techniques}

An observation grid provided information on the existence and use of management tools to assess administrative viability (Table 1).

Table 1. Methods of calculating indicators.

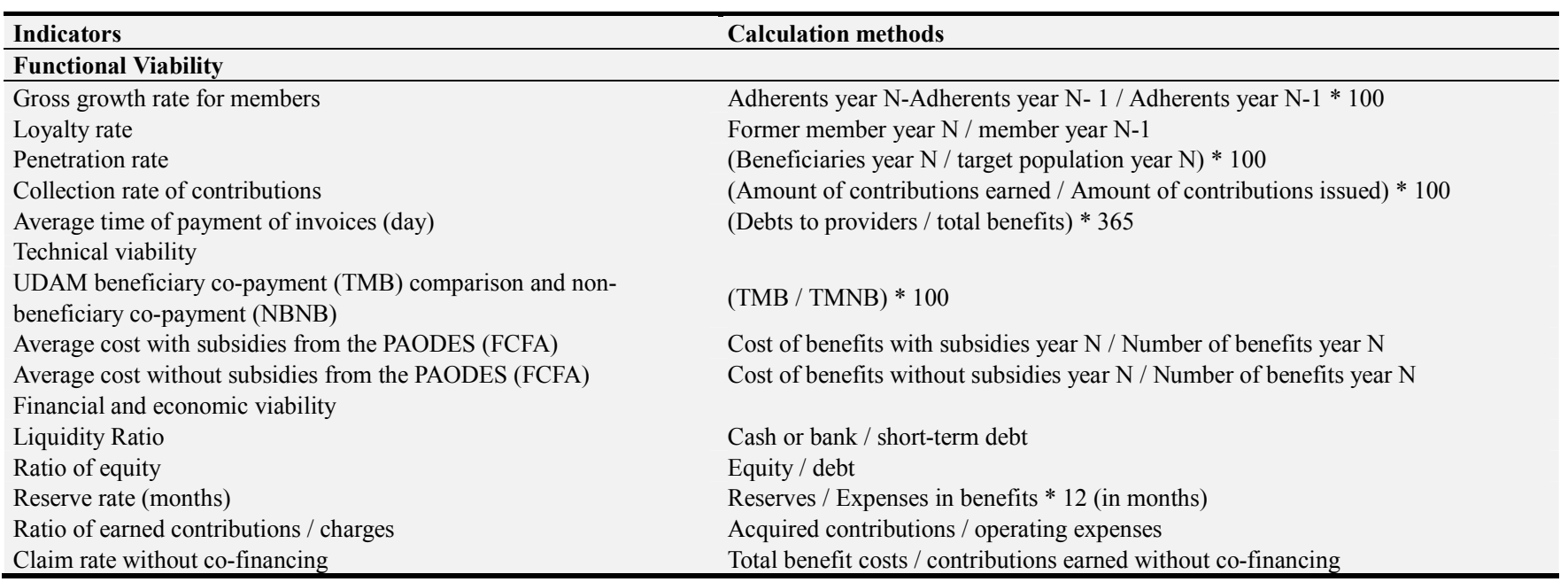




\begin{tabular}{ll}
\hline Indicators & Calculation methods \\
\hline Functional Viability & \\
\hline Claim rate with co-financing & Total benefit costs / contributions acquired with co-financing \\
Ratio of gross operating costs & Operating expenses / total revenues * 100 \\
Own financing rate & Total product / total expenses + hidden costs valued x100 \\
\hline
\end{tabular}

A data collection sheet was used to calculate indicators of technical, functional, financial and economic viability. A count of UDAM files available from 2014 to 2015 had been made (Table 2).

Table 2. UDAM data for the years 2014 and 2015.

\begin{tabular}{lll}
\hline \multirow{2}{*}{ Data } & years & $\mathbf{2 0 1 5}$ \\
\cline { 2 - 3 } & $\mathbf{2 0 1 4}$ & 1217 \\
Number of members & 398 & 12180 \\
Number of beneficiaries & 3471 & 161179 \\
Target population & 158,850 & $5,166,000$ \\
Benefit cost borne by the beneficiaries (FCFA) & 2619300 & $2,567,500$ \\
Subsidies of the PAODES (FCFA) & $1,337,500$ & $16,899,500$ \\
Cost of services supported by the UDAM (FCFA) & $7,418,600$ & 9742 \\
Number of services & 4156 & $12,686,578$ \\
Amount of contributions earned (FCFA) & $5,237,967$ & $30,842,353$ \\
Amount of contributions with co-financing (FCFA) & $14,337,116$ & $47,565,950$ \\
Amount of contributions issued with co-financing (FCFA) & $8,476,500$ & $16,899,500$ \\
Charges in benefits (FCFA) & $7,418,600$ & $30,866,928$ \\
Operating expenses (FCFA) & $10,089,500$ & 17499728 \\
Total products (FCFA) & 11897342 & 32650228 \\
Hidden costs (FCFA) & $11,872,800$ & $49,549,428$ \\
Total expenses (FCFA) & $19,291,400$ & \\
\hline
\end{tabular}

\subsubsection{Data Entry and Analysis}

The Microsoft Excel 2007 software was used to enter and analyze the data. The data analysis made it possible to calculate the UDAM administrative, technical, functional, financial and economic viability indicators using the formulas illustrated in Table 1.

The results were compared against International Labor Office (ILO) indicator standards (Table 3) [6].

Table 3. UDAM sustainability indicator scores.

\begin{tabular}{|c|c|c|c|}
\hline indicators & 2014 Score & 2015 Score & ILO standards \\
\hline \multicolumn{4}{|l|}{ Administrative viability } \\
\hline Membership tracking & 1 & 1 & 1 \\
\hline Collection of contributions & 1 & 1 & 1 \\
\hline Control of benefit entitlements & 1 & 1 & 1 \\
\hline Follow-up of those supported & 1 & 1 & 1 \\
\hline Monitoring of the risk portfolio & 1 & 1 & 1 \\
\hline Accounting follow-up & 1 & 1 & 1 \\
\hline Financial monitoring & 0 & 1 & 1 \\
\hline Total score & $\begin{array}{l}6 \\
85 \%\end{array}$ & $\begin{array}{l}7 \\
100 \%\end{array}$ & 7 \\
\hline \multicolumn{4}{|l|}{ Functional Viability } \\
\hline Gross growth rate for members & - & $206 \%$ & $>0 \%$ \\
\hline Gross growth rate for beneficiaries & - & $251 \%$ & $>0 \%$ \\
\hline Membership retention rate & - & $100 \%$ & $80 \%$ \\
\hline Penetration rate & $2 \%$ & $8 \%$ & $* * *$ \\
\hline Monthly collection rates of contributions & $169 \%$ & $65 \%$ & $100 \%$ \\
\hline Average time of payment of invoices (day) & 0 & 0 & According to agreements with providers \\
\hline \multicolumn{4}{|l|}{ Technical viability } \\
\hline Membership by voluntary family & 2 & 2 & 0 \\
\hline Portfolio quality (no consulting doctor) & Risks of abuse & Risks of abuse & - \\
\hline $\begin{array}{l}\text { UDAM beneficiary co-payment (TMB) comparison and non- } \\
\text { beneficiary co-payment (NBNB) }\end{array}$ & $\mathrm{TMB}<\mathrm{TMNB}$ & $\mathrm{TMB}<\mathrm{TMNB}$ & TMB $/$ TMNB $<1$ \\
\hline Average cost with subsidies from the PAODES (FCFA) & 1785 & 1735 & - \\
\hline Average cost without subsidies from the PAODES (FCFA) & 2106 & 1998 & - \\
\hline \multicolumn{4}{|l|}{ Financial and economic viability } \\
\hline Liquidity Ratio & Not applicable & & $>1$ \\
\hline Ratio of equity & Not applicable & & $>100 \%$ \\
\hline Reserve rate (months) & 0 & 0 & 06 months \\
\hline Ratio of earned contributions / charges & 0.7 & 0.7 & $>1$ \\
\hline
\end{tabular}




\begin{tabular}{llll}
\hline indicators & 2014 Score & 2015 Score & ILO standards \\
\hline Administrative viability & & & \\
\hline Loss ratio without co-financing & $142 \%$ & $133 \%$ & $75 \%$ approximately \\
Loss ratio with co-financing & $52 \%$ & $55 \%$ & $<15 \%$ \\
Ratio of gross operating costs & $85 \%$ & $176 \%$ & $>100 \%$ \\
Own financing rate & $62 \%$ & $35 \%$ & \\
\hline
\end{tabular}

For hidden costs, this is the estimated cost of the resources provided by UDAM free of charge.

\subsection{Qualitative Survey}

\subsubsection{Target Populations}

The study focused on the following populations: UDAM officials: the director, the manager, the two collectors and the president, Mutual members and non-members.

\subsubsection{Data Collection Tools and Techniques}

Individual interview guides were used for UDAM officials, members and a focus group guide for non-members. The topics addressed by UDAM officials concerned: the process of setting up the UDAM, the steps that led to the establishment of the UDAM, the management of UDAM's activities, the difficulties encountered during the collection of contributions, UDAM's contribution to the state of health of the populations, the strong and weak points of the UDAM.

For the members, the topics were: information on the functioning of the UDAM, the degree of confidence in the UDAM, the assessments on membership fees and contributions, the provision of care, participation in decision making.

A focus group guide was used for non-members of the UDAM. The topics were: the therapeutic route in the event of illness, the difficulties encountered in the health structures, the information on the existence of the UDAM, the acceptability of the UDAM, the reasons for non-membership to the UDAM, the wish to join the UDAM.

Individual interviews were conducted with UDAM officials. The 25 UDAM beneficiaries were interviewed at the UDAM headquarters or the Health Center at the time of the general consultations. For the establishment of the focus group, with the support of the District Chief Medical Officer, participants were contacted directly at the main door of the health center; volunteers who agreed to participate formed a group of 12 non-adherents. Participants benefited from clear and precise information on the objectives of the study and the freedom to accept or not to participate in the survey. All gave their verbal consent. The focus group lasted about 30 minutes.

\subsubsection{Data Analysis}

The analysis of the content of the individual interviews and focus groups made it possible to categorize the information according to their frequency of appearance. This key information related to the perceptions of the populations on the UDAM.

\section{Results}

\subsection{Quantitative Results}

\subsubsection{Administrative Viability}

At the end of the administrative viability analysis, the overall score for the quality of the monitoring was respectively $85 \%$ and $100 \%$ in 2014 and 2015. The UDAM showed shortcomings in the use of certain tools for management and monitoring of operations. These included deficiencies in the monitoring of the collection of contributions and membership fees, the monitoring of entitlement to benefits, monitoring of the risk portfolio and financial monitoring. Resolutions to these gaps remain important for the UDAM to be administratively viable (Table 3 ).

\subsubsection{Functional Viability}

The number of members and beneficiaries increased significantly in 2015. This result was attested to by the gross growth rates. The UDAM has a great capacity to retain its members. With gross growth rates of over $100 \%$ and a retention rate above $80 \%$, the UDAM registered many new members in 2015 . The penetration rate increased from $2 \%$ to $8 \%$. The monthly collection rates for 2015 ranged from $96 \%$ to $120 \%$. Having maintained these assets and increased UDAM's capacity to retain its members and register new members suggests that the departmental mutual is functionally viable (Table 3 ).

\subsubsection{Technical Viability}

The beneficiaries of the UDAM bore the costs of the covered benefits less than the non-beneficiaries. Apart from these advantages for the populations, the UDAM was subject to the major risks like the cases of over prescriptions, overconsumption and adverse selections. The technical viability of the UDAM is very threatened (Table 3 ).

At the posts and health center level, UDAM beneficiary copayment was lower than that of the non-beneficiary (Table 4).

Table 4. Comparison of user fees (FCFA) for beneficiaries and non-beneficiaries of the UDAM at the health post level.

\begin{tabular}{|c|c|c|c|}
\hline Features & $\begin{array}{l}\text { Moderator fee of the } \\
\text { beneficiary of the UDAM }\end{array}$ & $\begin{array}{l}\text { Moderator fee for the non- } \\
\text { beneficiary patient }\end{array}$ & $\begin{array}{l}\text { Beneficiary / non-beneficiary } \\
\text { ratio }\end{array}$ \\
\hline \multicolumn{4}{|l|}{ Health post } \\
\hline Consultation & 500 & 2000 & 0.25 \\
\hline $\begin{array}{l}\text { Childbirth and Emergency Care } \\
\text { Health center }\end{array}$ & 1000 & 5000 & 0.2 \\
\hline External consultation & 500 & 5000 & 0.1 \\
\hline
\end{tabular}




\begin{tabular}{llll}
\hline Features & $\begin{array}{l}\text { Moderator fee of the } \\
\text { beneficiary of the UDAM }\end{array}$ & $\begin{array}{l}\text { Moderator fee for the non- } \\
\text { beneficiary patient }\end{array}$ & $\begin{array}{l}\text { Beneficiary / non-beneficiary } \\
\text { ratio }\end{array}$ \\
\hline Pediatrics & 2000 & 10000 & 0.2 \\
Pediatrics $(<5$ years) & 2000 & 10000 & 0.2 \\
Internal Medicine & 3000 & 15000 & 0.2 \\
Minor surgery & 3000 & 15000 & 0.2 \\
Major Surgery & 5000 & 35000 & 0.14 \\
Obstetric gynecology & 1000 & 10000 & 0.1 \\
Delivery & 1000 & 7500 & 0.13 \\
Chronic diseases & 1000 & 10000 & 0.10 \\
\hline
\end{tabular}

\subsubsection{Financial Viability}

UDAM have any debts with the public health structures (posts and health center) of the Koungheul department. Membership fees were able to cover benefit costs and UDAM bore less with the co-financing of PAODES. The loss ratio remained high without co-financing (more than 100\%) exceeding the threshold (75\%). Without partner support, UDAM would have supported operating costs with operating expense ratios of $85 \%$ and $176 \%$ respectively in 2014 and 2015 (> 15\%). The financial viability of the UDAM remains compromised after the withdrawal of the partner (Table 3).

\subsubsection{Economic Viability}

The UDAM could not cover all of its expenses with its own funds. The 2014 and 2015 self-funding rates were 62\% and $35 \%$ respectively $(<100 \%)$. Similarly, the amount of contributions remained very low to support the total expenses. The financial support of the PAODES allowed the UDAM to pay part of the expenses excluding medical consumption. The economic viability of the UDAM would be threatened once this partner withdrew (Table 3).

\subsection{Qualitative Results}

\subsubsection{Individual Interviews with UDAM Officials}

\section{i. Process of setting up the UDAM}

This question made it possible to know what type of initiative was at the base of the creation of the mutual and whether the necessary conditions for the establishment of a health mutual were met. According to the director of UDAM: "Like any initiative to create a health mutual, the goal was to allow people throughout the Koungheul department to access quality health care at a lower cost. With the advent of flatrate pricing, health mutuals that were active in the department and had a few hundred beneficiaries up to date on contributions were no longer able to support the share of reimbursement of care benefits that they returned. In other words, these mutual health insurance companies did not have the financial viability that allowed them to reimburse health care benefits. It was necessary to set up a health insurance at the departmental level that would be able to fulfill its commitments to health care benefits." According to the chairman of the board: "Initially with universal health coverage (CMU) the state wanted to set up a solid health system based on flat rates. And for this it was necessary to have pilot areas, it is in this case that Koungheul and Foundiougne were chosen for the test phases. Then it engaged in discussion with the old mutuals until the solution according to which they could join the big mutual called UDAM (Departmental Unit Health Insurance)".

ii. Management of UDAM activities

The executive office at the central level ensures the control of management and field activities. According to the director of UDAM: "The absence of the UDAM executive office is explained by the desire to professionalize the departmental health insurance. The UDAM has an administrative council of 25 members including the 09 mayors of the communes of the department and a control body (cc) of 04 members. The executive board has been replaced by technical staff who are responsible for implementing the guidelines set by the board of directors. This technical staff consists of a director, an accounting manager, an administrative assistant and 02 collectors. In order to circumvent the constraints linked to the unavailability of the animators of traditional health mutuals who were volunteers, the staff of the UDAM is permanently in charge of animating with the aerials of local collectivities by carrying out all the field activities and by fully involving health care providers, local elected representatives, grassroots community organizations and deconcentrated state technical services ". The administrative assistant tells us about it: "UDAM officials can provide for each other. With the aerial committees, which are set up, they do work on communication and raising awareness for contributions at the field level."

iii.Difficulties encountered during the collection of contributions

The director listed these difficulties: the weakness of the purchasing power of the populations who are mostly farmers affected by poverty; the difficulty of accessing certain areas at certain times of the year; difficulty for the heads of households to contribute for family members; the absence of a culture of mutuality, which means that beneficiaries always evaluate their level of consumption of care in relation to their total contribution, linked to ignorance of the principle of solidarity; the internal organization in each village for collecting dues is not yet clear.

iv. Contribution of UDAM to the health status of populations

The director said: "The UDAM contributes to the improvement of health for several reasons: with the payment of the co-payment, the heads of household and their dependents no longer give up the care. The accessibility of the costs of medical care solves the problem of partial exclusion given the drugs to buy. Populations are less inclined to resort to traditional healers (decline in parallel 
practices). Populations no longer have valid reasons for resorting to health care late. The medical care of the beneficiary no longer waits on the head of household, the member, traveling. Health indicators are improved (reduction of maternal and infant-juvenile mortality, reduction of home deliveries)." Health indicators are improved (reduction of maternal and infant-juvenile mortality, reduction in home deliveries) as an example from 2013 to 2015, the rate of deliveries in structures had increased from $73 \%$ to $84,6 \%$ and a contraceptive prevalence rate of $8.85 \%$ to $18.7 \%$. According to the administration assistant: "If you belong to a mutual and you get sick you can be consulted with 500 FCFA for 2000 FCFA because 1500 FCFA are supported by the UDAM or 1000 FCFA for 10,000 FCFA because 9000 FCFA are the responsibility of the UDAM and the PAODES and having the right drugs.

v. Highlights of UDAM

This will allow the mutual to see where to rely on to perpetuate its existence.

The director quoted us some points: the professionalization which makes it that at any moment, there is staff which responds to the request of the members; the effective involvement of mayors and other local elected representatives in the animation of the community structure, which is supposed to facilitate the medical care of populations, health being a transferred competence; the availability of logistical means to carry out the field work; the technical and financial support of PAODES and the State to UDAM.

vi. Weaknesses of the UDAM

The president of administration explains to us: "The material resources are low while the department is vast. The high illiteracy rate of the population is a factor limiting their membership in the UDAM. The director added: "The population is slow to see the difference between UDAM and the previous mutuals that have experienced many difficulties, including the breakdown of partnerships with health care providers and the slowness on the part of the delegates of the aerials of local authorities to appropriate the UDAM and to get fully involved in its animation at the local level." According to the manager of UDAM "despite the practices of affordable contributions, some members have trouble paying their dues. That's why agents were hired to collect door-todoor dues. ".

\subsubsection{Individual Interviews with Members of UDAM}

\section{i. Information on the operation of the UDAM}

All members met acknowledged being informed about the operation of the mutual. Most of the beneficiaries (18/25) explained that a UDAM agent was passing through their homes to explain how the UDAM works. The others $(7 / 25)$ had the information through community radio.

The members (19/25) do not know the principles of mutuality based on mutual aid and solidarity between members.

ii. Degree of confidence of UDAM members and assessments of membership fees and contributions
In unanimity, the members we met felt that they had confidence in the managers of the mutual society. Some $(15 / 25)$ explain that they had confidence because the officials have carried out a sufficient communication by emphasizing the advantages of the UDAM compared to the basic mutuals that existed in the department. Others were reassured by their neighbors that are beneficiaries.

For all members, membership fees and fees are affordable. They recognized that joining the Mutual can significantly reduce the cost of access to health care. However, membership fees and contributions are considered high by some beneficiaries (7/25). According to the beneficiaries $(17 / 25)$ the benefits covered by the health district meet their needs. However, others (13/25) believe that the costs of benefits and medicines are quite high especially at the level of private pharmacies.

iii.Participation in decision-making

All the members met felt that they were not involved in the decision-making and life of this departmental mutual. According to a beneficiary: "The mutual is made for the beneficiaries and it lives off of our contributions, so it is quite normal that our opinions be taken into account. I suggest at least that we open a suggestion box at the entrance of the structure and inform members of the holding of general meetings." The managers of the mutual recognize this lack of information and the irregularity of meetings of statutory bodies.

\subsubsection{Focus Group Results for Non-members}

A focus group of 12 participants was realized.

i. Therapeutic route in case of illness

The health district is the first resort for any illness revealed a fraction of non-members. This, despite the parallel use of traditional medicines. According to one participant, although the first resort is the health center, they must always combine traditional medicines which are also sometimes more effective than modern treatment especially in children. "Those who do not use modern medicine point to the high cost of prescriptions prescribed in health facilities and poverty.

ii. Difficulties encountered in health structures

Non-adherents have all denounced the poor reception in the health structures and the behavior of some health workers: "They do not give respect to the patients, even to ask for information you go around the structure without satisfaction". The lack of qualified personnel available in the structures is also deplored: "You have to go to the clinics to meet the best doctors".

iii.Information on the existence of the UDAM

The principles of the mutual are largely unknown by the participants of the focus group. A minority has heard of mutual: "At some point some people came here to talk about the mutual, but we found that it was something not very clear. "Most non-adherents are aware of the existence of the UDAM. They were made aware by neighbors, health workers or UDAM and through community radio.

iv. Acceptability of the UDAM

The non-adherents of the UDAM believe that, like the 
associations and cooperatives, the mutuals are organizations managed by a minority and that only benefits itself: "Mutuals do not do their job and diversions are commonplace."

Others estimate that they have very little income to meet the priority needs of their families and categorically reject the idea of saving for an unlikely event. The tendency of some participants is indifference to the risk of the occurrence of diseases: "... anyway it is God who gives health or sickness, and no one can predict when it will happen..." However, UDAM is positively appreciated by some of the non-adherents For them, it allows them to have proximity to quality health care and cope with unannounced health expenses.

v. Reasons for non-accession to UDAM

Non-adherents unanimously evoke the high cost of living and poverty in households for avoiding joining the mutual. One of the participants said, I' cannot register my family at UDAM because membership fees and contributions are expensive and what I earn is not enough to support my household." Another said: "One day there was in our neighborhood a very poor patient who did not have enough to pay a for consultation ticket, we went to the market to make a collection so that he has enough to pay for his care".

vi. Wish to join the UDAM

Most of the non-members would like to join the UDAM but it is necessary that those responsible decrease the contributions. Others do not find the need to adhere; someone said: "I will not join the UDAM even for my family because with the free initiatives set up by the state we are covered."

\section{Discussion}

Membership in the UDAM is voluntary, familial. The UDAM recorded 2 as a score, which means that the risk of adverse selection is average. Unlike a private insurance system of a commercial nature, the mutual health insurance company cannot select its beneficiaries or charge each of them premiums corresponding to their personal risk.

According to Buter JD et al, a mutual health insurance is viable when it is designed and organized to the satisfaction of its customers and partners, it has guards who protect it against major risks such as adverse selection, the risk of escalation costs and is self-financing [7]. However, to minimize the risk of adverse selection, the UDAM required the minimum enrollment unit to be the family and introduced a two-month observation period or waiting period for new registrants according to the payment modality, monthly, semi-annual, or annual. This mandatory nature is a factor of non-adherence, especially since the members do not establish a link between such a formula and the need for the mutual to counter a selection adverse of risks (which occurs if the head of household only affiliates the most vulnerable members of his family, which obviously imbalances the insurance system) [8-10].

Managers should also strengthen advocacy with village and / or neighborhood leaders to advocate group membership to reduce the risk of adverse selection. Several authors have demonstrated the effect of information and awareness of the population on their membership of the mutual insurance, especially that they strengthen their confidence in the mutual. According to our context, this awareness must be based on the attractiveness factors of the UDAM; it is unifying with an extension of covered benefits such as chronic diseases. According to Basaza et al. (2008), the fact that Ishaka Mutual Health Insurance Company in Uganda does not take care of chronic diseases appears to be one of the causes of low enrollment rates [11]. A fortiori, the exclusion of a service would have a negative effect on the dynamics of membership [12]. To avoid escalating costs, the application of flat rate pricing has led to good cost control. According to Betsi E, the mutuals sometimes feel abandoned to themselves, the health mutuals are exposed to all forms of exploitation and the measures of security and protection of its heritage remain weak. The adverse selection is almost institutionalized; many cases of over-prescription and fraud exist. In his study, unlike ours, the prescription syndrome exists, the costs of the acts are not uniform and the costs of the benefits increase day by day. Thus, social control and the preservation of mutual benefit entitlements constitute one of the main advantages for community participation and the retention of members [13]. The members are a lever against the providers by defending their rights and therefore be more demanding. This place of beneficiaries in the management of the health mutual has been well described in the study by Criel B et al [14]. The UDAM must have a medical adviser to verify certain services delivered to UDAM beneficiaries in order to prevent abuse or fraud.

UDAM had monthly collection rates of contributions close to or above $100 \%$. In Ghana, the premium rate considered high was recognized as one of the reasons for the drop in the enrollment rate in mutual health insurance, which went from 8.3 points for the period $(2007-2008)$ to 6.5 points for the period (2008-2009) [15]. The analysis of the monthly contribution recovery rates shows that UDAM was recovering the maximum of its contributions. With respect to providers, UDAM pays care bills without delay or debt. These aspects reinforce the mutual trust between providers and UDAM managers at the services of these beneficiaries.

With the support of PAODES and the state in the form of grants, the claim rate increased from $52 \%$ to $55 \%$. The financial implication of the partner reduces the share of funding to cover the costs of services. This result demonstrates UDAM's ability to cope with expenses. This situation is partly explained by the good indicators recorded, namely the monthly recovery rates and the retention rate of around $100 \%$. Therefore, the UDAM has no debts vis-à-vis the health structures. In this case, all the entities are mutually beneficial: the population, the health structures, the UDAM and even the State. Adhering to the UDAM alleviates from the beneficiaries the expenses incurred for care. According to Kagambega MT, affiliation to a mutual insurance company can therefore significantly reduce the cost of health services [16]. The system of health insurance via the departmental mutuals has a positive impact on the expenses of care of the members of the mutual, on their health and perhaps even on the economy of the household [17]. Without co-financing, 
loss ratios were high $(\geq 75 \%)$; these results were higher than those found in J Kanyeshuli's study of the Musanze Mutual calculated at $72 \%$ [18]. This finding reveals a risk to financial viability because more the contributions earned do not cover the expenses. Similarly, the economic viability is threatened once this financial partner withdraws because it supported UDAM's operating and investment costs. Indeed, its own funds were insufficient to cover expenses. As a result, efforts must be made to collect contributions and to find mechanisms of financial autonomy, such as the creation of income-generating activities, and the recruitment of a medical adviser to ward off additional sources of expenditure. The UDAM can certainly control its operating costs but it cannot fully control the benefits it will support because the occurrence of disease is unpredictable. The state of Senegal through its universal health coverage program must further support the UDAM once the partner withdraws. This additional funding will cover non-medical expenses and the UDAM's own funds through membership fees can finance the object for which it exists. In addition, ACMU must also articulate free initiatives such as those targeting seniors, namely the Sésame Plan and the UDAM targeting the indigent through the National Health Equity Fund [19].

The main criteria for assessing the quality of care provision are reception (availability of health care providers, waiting times, respect and consideration on the part of carers), prescription and availability of medicines and the speed of the results of diagnosis [20]. This study based on a normative evaluation using the ILO reference framework [6] does not take into account the quality of the offer at the district level of Koungheul, this tool is interested in the demand side of health. Similarly, the deepening of the qualitative survey on the issue of supply among UDAM beneficiaries, non-beneficiaries and service providers could have made it possible to understand the behavior of these different targets. Thus, the evaluation of the quality of the health supply could have provided, on the one hand, information on cases of over-prescription among providers or of abuse such as moral hazard among beneficiaries and, on the other hand, identifying non-adherence factors related to the provision of care among non-UDAM beneficiaries.

\section{Conclusion}

The mutual may be an alternative to access to care. It is a focal point in the strategic plan for universal coverage. Thus, the Ministry of Health of Senegal with the support of PAODES is experimenting with an initiative to promote the departmental unit of health insurance in the health district of Koungheul. The study of the viability of the UDAM shows that at the administrative level, there is a good overall score of quality of the follow-up of the functioning but there is a lack of verification of the validity of the attestations of care, the list of those excluded from provision of services and the monitoring of beneficiary registration by providers. Functionally, the UDAM registered many new members in 2015. In addition, the risk of adverse selection and the absence of a medical adviser threaten the technical viability of the UDAM. In financial and economic terms, contributions are still insufficient to cover operating and investment costs. With the financial support of PAODES, UDAM has managed to meet the expenses, but its withdrawal will compromise its financial and economic viability. This study showed that UDAM is not viable. Thus, to ensure the viability of the mutual in all its dimensions, it seems appropriate to strengthen the communication to the populations with a view to a mass membership, to increase the equity of the UDAM by additional funding of ACMU and the reduction of the covered benefits package such as those of chronic diseases to reduce the cost of care.

In perspective, it is important to carry out a study of the estimated costs of this departmental mutual to estimate the shares supported by the UDAM and the CAEP and to evaluate the relevance of the unitary contribution for a good control of the loads.

\section{Acknowledgements}

We sincerely thank the responsible for the UDAM of Koungheul and the member and no-member of this mutual who accepted to participate in this study.

\section{Competing Interests}

The authors declare no conflict of interest. This research received no external funding.

\section{References}

[1] National Agency of Statistics and Demography. Demographic and Health Survey with Multiple Indicators in Senegal 201011 (EDS-MICS). Dakar: ANSD; 2012; 482p.

[2] NHDP. National Health Development Plan 2009-2018. Dakar: MSAS; January 2009; 86p.

[3] CIDR, GTZ et al. Report of the evaluation mission of the "Strengthening Community Capacity" component of GTZ. March 2005.

[4] Ministry of Finance. Report of the Senegal Poverty Monitoring Survey ESPS 2005-2006. Dakar: ANSD; August 2007; 63p.

[5] National Agency of Statistics and Demography (ANSD). Report on the General Census of Population and Housing, Agriculture and Livestock (RGPHAE) 2013. Dakar: ANSD; March 2014; 63p.

[6] International Labor Office-International Center for Development and Research. Guide for monitoring and evaluating health microinsurance schemes. Geneva: ILO / STEP; 2001; 102p.

[7] Butera J D. Effect of national mutual health guarantee fund on the use of health services in district and national referral hospitals. National University of Rwanda: School of Public Health. 2009. 
[8] From Allegri M, Sanon M, Sauerborn R. To enrol or not enrol? A qualitative investigation of demand for health insurance in rural West Africa, Social. Science Medicine. 2006a; 62 (6): 1520-1527.

[9] Criel B., Barry A., Von Roenne F. The PRIMA project in Guinea Conakry. An experience of organization of mutual health in rural Africa. Brussels: Medicus Mundi Belgium; 2002; 255P.

[10] Criel B, Waelkens MP. Declining subscriptions to the Maliando Mutual Health Organization in Guinea-Conakry (West Africa): what is wrong? Social Science Medicine. 2003; 57 (7): 1205-1219.

[11] Basaza R, Criel B, Van Der Stuyft P. Community health insurance in Uganda: Why does enrolment remain low? A view from beneath. Health Policy. 2008; 87 (2): 172-184.

[12] Fonteneau B. The challenges of health micro-insurance policies in West Africa. Policy framework, institutional environment, functioning and sustainability. Hoger Instituut voor de Arbeid, Leuven. 2004.

[13] Emmanuel M B. Evaluation of the mutual health insurance of Manjo state of the places, analysis of the problems and proposal of the measures of adjustment. Evaluation 1. Manjo (Cameroon): Provincial Cell of Promotion and Development of Health Mutuals. Provincial Unit for Promotion and Development of Mutual Health / GTZ; April 2010. 65p.

[14] Criel B, Blaise P, Ferette D. Health Mutuals in Africa and quality of care in services: a dynamic interaction. in $G$ Dussault, P Fournier, A Letourmy (eds), Health Insurance in Francophone Africa; improve access to care and fight against poverty. Health, Nutrition and Population Series, International Bank for Reconstruction and Development / The World Bank, Washington, 2006: 353-372.

[15] Nsiah-Boateng E, Aikins M. Performance assessment of Ga district mutual health insurance scheme, Greater Accra Region, Ghana. Value in health regional issues. 2013; 2: 3005 .

[16] Toussiida Kagambega M. Low-income populations and health protection in Burkina Faso: the conditions for people's adherence to mutualist principles. Sociologies; 2014.

[17] Meessen B, Criel B, Kegels G. Formal arrangements for pooling health risks in sub-Saharan Africa: ways to think about obstacles encountered. International Social Security Review. 2002; 55: 91-116.

[18] Kanyeshuli J. and Kakoma JB. Study of the viability of health mutuals: case of the health mutual of the district of Musanze / Rwanda (2006-2008). Rwandan Medical Review. 2010; 68 (4): 41-46.

[19] Leye MM M M Diongue, Faye A, Coumé M, Faye A, Tall AB Niang K Wone I, Seck I, P Ndiaye, Tall A Dia. Analysis of the operation of the free care plan for elderly people "Plan Sesame" in Senegal. Public health. 2013; 1 (25): 101-106.

[20] Waelkens MP, Criel B. Mutual health insurance in subSaharan Africa. State of play and reflections on a research agenda, HNP Discussion Paper, World Bank, Washington DC. 2004. 